Doi: 10.5212/Uniletras.v.43.18306.2021

\title{
LITERATURA E AUDIOVISUAL: UMA RELEITURA DE EDGAR ALLAN POE EM “CONTOS DO EDGAR”
}

\author{
LITERATURE AND AUDIOVISUAL: A REREADING OF \\ EDGAR ALLAN POE IN "CONTOS DO EDGAR"
}

Dudlei Floriano de Oliveira"

Alfeu Sparemberger**

Resumo: O processo de transposição cultural e temporal é um recurso frequente que leva em conta questões como as mudanças presentes no contexto de produção do texto fonte para o contexto do produto adaptado. Estudado por Hutcheon (2013) e cunhado por Genette (1997) como Aproximação, esse processo busca aproximar diferentes obras narrativas para contextos mais próximos de seus respectivos públicos, seja em termos culturais, temporais ou geográficos. Edgar Allan Poe tem suas obras constantemente transpostas para diferentes contextos culturais. Este trabalho busca, assim, analisar a produção audiovisual Contos do Edgar (2013), que adapta contos de Poe ao contexto urbano brasileiro do século 21, levando em conta questões sobre o Gótico e sobre transposição cultural e midiática, e como esses processos dialogam tanto com o texto fonte quanto com seu público-alvo.

Palavras-chave: Edgar Allan Poe. Contos do Edgar. Aproximação.

Aвstract: The process of cultural and temporal transposition is an usual device concerned with the changes that take place from the source text towards the adapted product. Studied by Hutcheon (2013) and coined by Genette (1997) as Proximization, this process aims at bringing different narratives closer to their respective audiences, whether in cultural, temporal or geographical terms. Edgar Allan Poe has his works constantly transposed to different cultural contexts. Therefore, this paper intends to

\footnotetext{
"Doutorando em Letras pela Universidade Federal de Pelotas (UFPel), Mestre em Letras pela Universidade Federal do Rio Grande do Sul (UFRGS) e graduado em Letras Português/Inglês pela Universidade Federal do Rio Grande (FURG). Atua como docente no Instituto Federal Rio Grande do Sul (IFRS). E-mail: dudlei.oliveira@gmail.com.

"Doutor em Letras pela Universidade de São Paulo (USP), Mestre em Letras pela Universidade Federal de Santa Catarina (UFSC) e graduado em Letras pela Universidade Regional do Noroeste do Estado do Rio Grande do Sul (UNIJUÍ). Atua como docente no Programa de Pós-Graduação em Letras da Universidade Federal de Pelotas (PPGL - UFPel). E-mail: alfeu.sparemberger@outlook.com.
} 
analyze the audiovisual production CONTOS DO EDGAR (2013), a show that adapts Poe's short stories into the urban Brazilian setting of the 21st century. This work will also consider the Gothic, cultural and midiatic transposition, and how these processes dialogue with both its source texts as well as with its target audience.

Keywords: Edgar Allan Poe. Contos do Edgar. Proximization.

\section{INTRODUÇão}

A obra de Edgar Allan Poe é uma das mais lidas, estudadas e difundidas no mundo ocidental, seja nos inúmeros cursos e projetos de pesquisa acadêmicos em âmbito de Graduação e Pós-Graduação, seja por milhares de leitores que buscam sua obra por mero prazer literário. Tal interesse por parte tanto da academia quanto de leitores em geral aponta para uma importância e relevância da obra de Poe, que perdura dois séculos após seu nascimento. Mais do que isso, o alcance de sua obra passa por complexas questões de transposição, releituras e tradução, posto que grande parte dela permanece sendo traduzida e comercializada em diferentes países, além de ser reproduzida em outras mídias.

Considerando-se a preponderância que a obra de Edgar Allan Poe apresenta nos dias de hoje em diferentes contextos sociais e culturais, o objetivo deste trabalho é o de analisar o processo de transposição que ocorre a partir da série de televisão intitulada Contos do Edgar, uma produção brasileira de 2013 que, conforme sugerido pelo título, adapta contos de Edgar Allan Poe para a linguagem audiovisual da televisão. Além de ser uma adaptação entre texto literário e linguagem audiovisual, Contos do Edgar realiza uma transposição cultural, geográfica e temporal da obra de Poe, trazendo os contos para o contexto urbano brasileiro da contemporaneidade. Desta maneira, o processo de adaptação e de transposição passa por diferentes questões, que envolvem desde as características diegéticas e midiáticas entre literatura e audiovisual, até questões extradiegéticas e socioculturais, abordando problemáticas do contexto brasileiro urbano da atualidade.

Para tal análise, este trabalho procura discutir autores que trabalham questões de intertextualidade, como Gérard Genette e Linda Hutcheon, numa perspectiva de se entender como esses processos de transposição entre diferentes linguagens ocorrem. Além disso, por ser Edgar Allan Poe um dos grandes nomes da literatura gótica, e pelo fato de a série analisada também se propor a manter o elemento Gótico em sua narrativa, autores que teorizam sobre a literatura e outras formas narrativas góticas também serão apresentados ao longo da análise, numa busca para se compreender o que torna Poe Gótico e o que torna Contos do Edgar também uma obra audiovisual gótica nessa transposição para o século 21. 


\section{RELEITURAS E TRANSPOSIÇÕES MODERNAS}

Não raro encontramos listas de filmes ou programas de televisão famosos com elenco conhecido e sucesso de bilheteria e audiência que, para surpresa de grande parte do público, são releituras de clássicos da literatura. Filmes como As Patricinhas de Beverly Hills (1995) ou O Diário de Bridget Jones (2001) causam certo espanto em muitos ao descobrirem que, por trás de narrativas aparentemente tão "modernas", há uma forte inspiração e adaptação dos clássicos de Jane Austen: Emma (1815) e Orgulho e Preconceito (1813), respectivamente. A surpresa talvez ocorra porque, para quem ainda não leu os livros, pode parecer difícil ou até impossível a ideia de que obras literárias da Inglaterra Regencial possam ter suas narrativas transpostas para cenários contemporâneos, mantendo muitos de seus elementos diegéticos originais e conseguindo dialogar com suas novas propostas de releitura.

Esse fenômeno de transpor uma narrativa mais antiga para um período e local mais próximo do público que o irá consumir é um fenômeno que o intelectual francês Gérard Genette vai classificar como "Aproximação". Como o próprio termo sugere, há um processo no qual se busca "aproximar" uma obra de seu contexto de produção:

Conforme foi indicado em referência à nacionalidade, o habitual movimento de transposição diegética é um movimento de Aproximação: o hipertexto transpõe a diegese de seu hipotexto para atualizá-lo e aproximá-lo de seu público (em termos temporais, geográficos ou sociais) (GENETTE, 1997, p. 304, minha tradução).

Os filmes supramencionados seriam exemplos desse processo: As Patricinhas de Beverly Hills transpõe os protagonistas de Emma para outro contexto: Emma Woodhouse e George Knightley deixam a Inglaterra Regencial para viver em Beverly Hills da década de 90 do século 20, agora sob os nomes Cher Horowitz e Josh Lucas, respectivamente. Apesar das (muitas) mudanças ocorridas no filme em comparação com a narrativa do livro, os conflitos pessoais, psicológicos e familiares da protagonista se mantêm por intermédio de uma personagem que, embora bem-intencionada, precisa sofrer e amadurecer para aprender que suas boas intenções nem sempre lhe permitem ter o melhor julgamento sobre os outros e sobre si mesma.

Em O Diário de Bridget Jones não temos mais as cinco irmãs Bennet preocupadas com o casamento como garantia de sustento familiar. No lugar de Elizabeth Bennet, Bridget Jones é uma jovem adulta solteira, com independência financeira, vivendo em uma Londres contemporânea, que pode aproveitar os prazeres - e sofrer as decepções - da vida de solteira com seus muitos encontros românticos nem sempre terminando de forma romântica. Desaparecem as restrições financeiras e sociais das mulheres inglesas do início do século 19, mas Bridget 
Jones, como Elizabeth Bennet, precisa aprender a sobrepujar os próprios preconceitos para conseguir se entender consigo mesma e com seus possíveis pretendentes ${ }^{1}$.

Esse processo, embora muito comum na atualidade com centenas ou milhares de filmes, telenovelas e séries que atualizam textos clássicos e mais antigos, não é algo recente. $\mathrm{O}$ próprio Genette, ao abordar a questão, mostrou como, já pelos séculos 18 e 19, diferentes países buscaram criar para si suas próprias versões de "heróis nacionais", como Robinson Crusoé. Tal tipo de releitura não é um fenômeno raro, ocorrendo há alguns séculos, e que aponta para uma necessidade de adaptação - no sentido "evolucionista" da palavra - para que certas obras possam "sobreviver" a outros contextos de recepção.

Para ilustrar a questão, Linda Hutcheon (2013) destaca o caso das peças de William Shakespeare, que continuaram sendo encenadas na Alemanha tanto na Primeira quanto na Segunda Guerra Mundial:

Na Alemanha, por exemplo, as obras de Shakespeare foram apropriadas por traduções românticas e, através da afirmação da afinidade germânica do bardo, utilizadas para gerar uma literatura nacional alemã. Por estranho que possa parecer, é por essa razão que as peças do maior dramaturgo dessa cultura inimiga continuaram sendo encenadas - com variações significativas que poderiam ser chamadas de adaptações durante as duas Grandes Guerras (p. 48).

Por meio de uma adaptação que envolve uma preocupação com questões políticas, a Alemanha permite-se continuar a celebrar o maior dramaturgo da Inglaterra, país com quem esteve em guerra nas décadas de 10 e 40 do século 20 . O caso apresentado de Shakespeare talvez seja um caso menor nesse tipo de exemplo de Aproximação, uma vez que as alterações feitas não chegam a configurar as mudanças ocorridas, como em O Diário de Bridget Jones em sua relação com Orgulho e Preconceito. Mesmo assim, esse é um bom exemplo de como, para "sobreviver", muitas obras artísticas precisam passar por algum tipo de adaptação para serem aceitas por outros públicos.

Um exemplo que merece destaque é o ocorrido com a obra de H. P. Lovecraft. Por ser um escritor que produziu muitas obras de horror, suspense, ficção científica e fantasia, além de importantes textos críticos sobre esses gêneros, trata-se de um nome que, assim como Edgar Allan Poe ou H. G. Wells, possui uma obra vasta e extremamente relevante para fãs e estudiosos dessa literatura. Há, porém, uma questão que pode gerar frustração, rejeição e, até mesmo, o movimento de "cancelamento" da atualidade: Lovecraft era abertamente xenófobo,

${ }^{1}$ Vale aqui uma menção especial a O Diário de Bridget Jones. Enquanto As Patricinhas de Beverly Hills é uma "adaptação direta" do livro Emma, O Diário de Bridget Jones passa por outros tipos de adaptação ou transposição: há uma série de televisão da BBC, de 1995, com Colin Firth no papel de Mr. Darcy. Essa série serviu como inspiração para o livro O Diário de Bridget Jones, de Helen Fielding, publicado em 1996 e, posteriormente, virou o filme homônimo em 2001. Assim, temos um caso aqui de intertextualidade e/ou adaptação que ocorre em diferentes etapas. 
racista, homofóbico e antissemita. Em diversas cartas e outros textos, o escritor deixava claro seu posicionamento de que via pessoas não brancas, judeus e homossexuais como seres inferiores. O crítico Max Valarezo afirma que os monstros criados por Lovecraft seriam a expressão de como o autor enxerga essas pessoas: seres repulsivos e nojentos (VALAREZO, 2020). Sendo, porém, sua obra tão significativa, mas o autor o representante de ideias tão retrógradas e perigosas, como achar um equilíbrio entre admirar a arte e condenar o artista? A resposta está justamente em processos de adaptação e de aproximação.

Dada a importância da obra lovecraftiana, cursos de Letras, editoras e outros profissionais da literatura e das artes narrativas correriam o risco de ter um grande vácuo artístico e referencial se a obra de Lovecraft fosse simplesmente expurgada das bibliotecas e livrarias. Assim, uma maneira que a sociedade atual encontrou para, ao mesmo tempo, preservar sua contribuição artística e acadêmica, mas também criticar o artista enquanto reprodutor de discursos perigosos, é por meio de obras audiovisuais que propõem a releitura de textos ficcionais lovecraftianos com uma ressignificação de temas como homofobia, racismo e preconceito.

Em 2007, o filme Cthulu buscou essa ressignificação. Tal filme, livremente baseado no livro A Sombra de Innsmouth, de Lovecraft, transpõe a diegese da primeira metade do século 20 para o início do 21 . No livro, um jovem se vê obrigado a passar a noite numa cidade que abriga criaturas cósmicas. No filme, o protagonista também se vê obrigado a passar a noite numa cidade que representa perigo para ele, mas, desta vez, o horror não surge de criaturas monstruosas, mas de seres humanos. O protagonista é homossexual e precisa proteger-se de uma população extremamente conservadora e preconceituosa, a ponto de serem tão violentos e perigosos quanto os monstros do livro. A ideia de perigo se mantém, mas a temática mudou, estabelecendo, simultaneamente, uma homenagem ao legado literário de Lovecraft e uma crítica ao seu legado humano.

Algo semelhante ocorre com a série Lovecraft Country: partindo do universo fictício de Lovecraft, a série tem como protagonistas personagens negros - algo impensável para Lovecraft - que passam pelas tribulações da segregação racial do sul dos Estados Unidos da década de 50 do século 20. A série apresenta elementos fantásticos como na obra de Lovecraft, mas é na reconstituição das leis segregacionistas - que realmente existiram - que o verdadeiro senso de horror ocorre. Desta maneira, mostra-se que uma obra importante não pode ser simplesmente ignorada ou banida, ainda mais quando ela já foi tão difundida ao longo das décadas por diferentes grupos etários e sociais. Os processos de adaptação e aproximação, porém, permitem que muitas obras sejam revisitadas, recriadas e ressignificadas, como uma maneira de encontrar um equilíbrio entre aquilo que deve ser homenageado e aquilo que precisa ser repensado e adaptado para sobreviver em novos contextos de recepção, uma vez que cada contexto possui demandas e traumas diferentes. 


\section{O GóTICO: EXPRESSANDO MEDOS EM DIFERENTES ÉPOCAS}

Quando o termo "literatura gótica" é usado, o que primeiro vem à mente de muitos leitores é uma estética que tem seus grandes precursores nos séculos 18 e 19. Tal entendimento é compreensível, posto que algumas das mais representativas obras góticas foram escritas neste período. Entre alguns desses clássicos podemos citar O Castelo de Otranto (1764), de Horace Walpole, considerado o primeiro romance gótico, além de outras obras como Frankenstein (1818), de Mary Shelley, e Drácula (1897), de Bram Stoker. O Gótico, porém, não é um movimento artístico limitado a um recorte espacial e temporal. Embora os séculos 18 e 19 sejam vistos como um período importante para a formação desta estética, o século 20 e o início do 21 continuam a produzir diferentes expressões artísticas góticas. O livro The Cambridge Companion to Gothic Fiction, uma coletânea de ensaios sobre o Gótico publicada em 2002, apresenta o mesmo como uma estética que, embora possa ter seu início marcado pelos escritos de Horace Walpole no século 18, não chega a ter um término. O livro abre com uma cronologia de diferentes fatos históricos e obras importantes desta estética. Além de citar os grandes nomes da literatura gótica dos séculos 18 e 19, a cronologia engloba obras como filmes e programas de televisão, incluindo eventos históricos e contribuições científicas que ajudam no entendimento do Gótico, como os estudos de Sigmund Freud e as mudanças decorrentes de conflitos bélicos. A coletânea encerra sua lista de obras góticas, no ano de 2001, com o filme Os Outros, de Alejandro Amenábar. Como o filme foi lançado apenas um ano antes da publicação do livro pode-se inferir que, caso o livro venha a ser reeditado no futuro, a cronologia poderia incluir novas obras consideradas góticas. Desta maneira, é possível concluir que o Gótico não está limitado a um período histórico. Mais do que isto, pode-se afirmar que o Gótico está presente em diferentes contextos, renovado em múltiplas épocas e linguagens.

No ensaio The contemporary Gothic: why we need it ${ }^{2}$, de Steven Bruhm, presente no compêndio, o autor discute diversas obras consideradas góticas, tanto literárias quanto audiovisuais, estabelecendo conexões de obras contemporâneas com obras setecentistas e oitocentistas, mostrando como o Gótico se introduz em diferentes contextos histórico-sociais. Se o Gótico pode ser observado em um amplo e diverso conjunto de obras, o que poderia caracterizar, por exemplo, que tanto uma obra como Jane Eyre, escrita em meados do século 19, na Inglaterra, e Entrevista com o Vampiro, escrita no final do século 20, nos Estados Unidos, sejam ambas consideradas Góticas? Um possível conceito sobre a estética gótica seria "uma atmosfera medieval com um contexto medieval - castelos solitários, torres assombradas, passagens subterrâneas, cavaleiros em armaduras, mágica" (LONGUEIL, 1923, p. 458, minha tradução). Considerando que o Gótico vai além, tanto em termos temporais quanto geográficos da "atmosfera medieval", é importante salientar que ele, mesmo quando apresentando em suas narrativas um contexto diferente do medieval,

2"O Gótico Contemporâneo: por que precisamos dele", em tradução livre. 
uma narrativa gótica geralmente se passa [...] em um lugar antigo ou com aparência de antigo [...]. Neste espaço, ou em uma combinação de tais espaços, estão escondidos alguns segredos [...] que assombram as personagens, psicologicamente, fisicamente, ou de outras maneiras ao longo da história (HOGLE, 2002, p. 2, minha tradução).

O conceito de "lugar antigo ou com aparência de antigo", situado em contextos medievais nas primeiras manifestações de ficção gótica, denota um cenário de ruínas, quando as personagens têm a sua paz "deteriorada”. Conforme vemos em outras obras góticas produzidas nos séculos seguintes, o espaço representado na ficção gótica é simbólico de um confronto entre possíveis dicotomias, como consciente $x$ inconsciente ou real $x$ sobrenatural. O Gótico surge como uma estética que trabalha com estes conflitos representantes de medos e traumas vividos por indivíduos ou sociedades. Em seu ensaio, Steven Bruhm (2002), ao comparar diferentes obras góticas, declara que "o Gótico sempre foi um barômetro das ansiedades que assombram certa cultura em determinado momento histórico [...]”3 (p. 260, minha tradução). Assim, mais do que um movimento artístico circunscrito em uma época, representado apenas por obras com semelhanças estruturais, o Gótico ultrapassa essas questões, manifestando-se de diferentes formas e épocas, uma vez que pode ser compreendido como a expressão artística de certos anseios e medos experienciados por diferentes grupos sociais e culturais. Ao, portanto, tentar-se comparar obras produzidas em contextos diferentes, é importante compreender que o que vai permitir a caracterização de determinadas obras como góticas está na representação artística dos medos vividos em seus respectivos contextos culturais e históricos, em que há alguma espécie de ruína, concreta ou simbólica, que coloca conceitos opostos em conflito.

Como visto anteriormente em relação aos processos de aproximação, um exemplo recente de Aproximação de narrativa gótica é o caso do filme, de 2020, O Homem Invisível. Baseado no romance homônimo de H. G. Wells, o filme é transposto para o século 21 e tem como protagonista não mais o cientista do livro, mas uma mulher, ex-esposa desse cientista. No filme, o cientista passa a ser o antagonista, um homem violento que espanca sua esposa. Após ser dado como morto, a protagonista sente que ele ainda a está ameaçando e perseguindo, e isso torna-se o principal fator para que ninguém creia nela.

Trazendo novamente o conceito de que o Gótico serve como uma metáfora para os anseios de diferentes contextos culturais em distintos momentos históricos, a aproximação do filme, ao colocar o cientista como antagonista e sua esposa como protagonista, dialoga com um dos grandes temores sociais da atualidade, que é a violência contra a mulher e os inúmeros casos de feminicídio ao redor do mundo. Ao usar o tema da invisibilidade, o filme aborda a questão sobre como o feminicídio é um caso que sofre certa "invisibilidade social": assim como a protagonista, que se sente constantemente ameaçada, mas não consegue tornar seu algoz "visível”, muitos casos reais de feminicídio são também “invisíveis" para a sociedade

${ }^{3}$ The Gothic has always been a barometer of the anxieties plaguing a certain culture at a particular moment in history [...]. 
enquanto estão no plano da ameaça, sendo, muitas vezes, perceptíveis somente quando essa perseguição se concretiza em agressão física - com feridas aparentes, pois quando a violência não é aparente a vítima costuma ser constantemente desacreditada -, ou, então, somente quando a agressão chega ao assassinato. Logo, temos aqui um caso que combina bem essas duas questões: a Aproximação e o Gótico. Ao transpor uma narrativa clássica da literatura gótica para os dias atuais, não se buscou simplesmente contar a mesma história mais uma vez, mas causar o senso de horror com um problema social real que, com efeito, causa ansiedade, medo, violência e, infelizmente, até mesmo a morte de muitas mulheres ao redor do mundo.

\section{Contos do Edgar: Relendo Edgar Allan Poe no Brasil}

Em 2013 o Brasil passava por grandes transformações sociais, econômicas e políticas, o que incluiu novos incentivos e leis para a produção audiovisual nacional. Uma dessas leis é a Lei $n^{\circ} 12.458$ de 2011, que obrigava os canais de entretenimento em serviços de TV a cabo a exibirem, pelo menos, 3 horas e 30 minutos semanais de programação nacional no horário nobre, o que gerou uma grande mudança na produção audiovisual brasileira. Neste contexto, surge a série Contos do Edgar, produzida por Fernando Meirelles e exibida no canal de TV a cabo Fox Brasil, que transpõe diferentes elementos do universo literário de Edgar Allan Poe para o contexto urbano brasileiro do século 21, mais precisamente na cidade de São Paulo, grande centro financeiro e cultural do país.

A série divide-se em cinco episódios, todos intitulados pelos nomes de suas protagonistas femininas: "Berê", "Cecília”, "Íris", "Priscila” e "Lenora”. De acordo com os créditos de abertura da série, os episódios são inspirados nos seguintes contos: Berêe é inspirado em Berenice; Cecília é inspirado em A Máscara da Morte Rubra; Íris é inspirado em O Coração Delator; Priscila é inspirado em Metzengerstein; e Lenora é inspirado em O Gato Preto e em O Barril de Amontillado.

Embora a série seja dividida em episódios, cada um com uma história e protagonista independente, há um arco narrativo que os conecta. A série, que se intitula Contos do Edgar, tem esse nome não apenas como referência a Edgar Allan Poe, mas, também, como referência a Edgar, personagem que pode ser considerado protagonista do programa. Assim como Poe, que teve uma vida marcada por infortúnios e mistérios - como os reais eventos de seus últimos dias de vida, que alimentam a imaginação de seu público -, o protagonista Edgar é apresentado como alguém perturbado e cheio de segredos, que vão sendo revelados aos poucos ao longo da série. Em uma clara referência ao conto O Barril de Amontillado, uma das poucas coisas que o público sabe sobre Edgar é que seu melhor amigo se chama Fortunato, dono de uma dedetizadora denominada "Nunca Mais", uma apropriação do refrão, na tradução em língua portuguesa, do poema O Corvo, um dos grandes expoentes da literatura gótica por colocar em conflito importantes visões da vida, como a sabedoria e o conhecimento lógico (o busto de Palas 
Atena) em oposição ao misterioso e o sobrenatural (o corvo), contribuindo para uma atmosfera ameaçadora que não consegue ser desfeita. Ainda com base nesse poema, sabemos, logo no primeiro episódio, que Edgar seria casado com uma mulher chamada Lenora. Esta relação entre Edgar, Fortunato e Lenora é o arco narrativo que atravessa todos os episódios da série, posto que a natureza dessa relação é apresentada aos poucos, criando um mistério inicial que vai sendo construído até ser totalmente revelado no último episódio - esse intitulado Lenora.

A maneira como os outros episódios são costurados ao conflito de Edgar é simples, mas eficiente: Fortunato e Edgar são chamados para dedetizar as residências e comércios que servem de cenário para os diferentes episódios da série. Já nesse início percebe-se um grande contraste entre eles: enquanto Fortunato apresenta-se como uma espécie de "porta-voz" da dupla e da dedetizadora, sempre de forma extrovertida e até exagerada - tanto com seus clientes quanto com Edgar -, este já se mostra como o oposto, introspectivo e introvertido, preferindo mais os monólogos que os diálogos. Ambos lidam com os mesmos clientes, mas a reação de cada um é bem diferente. Fortunato sabe conversar com seus clientes, mas não parece se preocupar muito com a verdadeira situação de cada um deles, além daquela que ele pode resolver de forma profissional. Já Edgar aparenta ter certa falta de empatia pelas pessoas com quem ele lida, mas é ele quem realmente reflete sobre os problemas de seus clientes que, diferentemente das infestações de insetos, não podem ser simplesmente resolvidos com uma aplicação de pesticida. Afinal, esses problemas apresentam camadas psicológicas, sociais e afetivas muito mais profundas.

Parte desta reflexão de Edgar é exposta ora como narração em voice over ora em monólogos do próprio Edgar, evidenciando este como alguém mais introspectivo. Tal reflexão também sugere possível semelhança entre Edgar, protagonista da série, e Poe, o escritor: ambos são possíveis testemunhas e até vítimas do horror de suas narrativas. ${ }^{4}$

Muitos dos monólogos de Edgar sugerem segredos envolvendo ele, seu amigo Fortunato e a esposa Lenora. Além disso, algo que torna seu discurso mais carregado e até ameaçador é a chegada de um pombo, na dedetizadora, diante de Edgar. Novamente outra explícita referência ao poema O Corvo, texto que relata a tristeza de um homem viúvo - assim como o protagonista da série, Edgar, que está sofrendo com a ausência da esposa - que se vê obrigado a verbalizar seus medos com a chegada de um corvo em uma fria noite de inverno.

A escolha por um pombo, na série de televisão, ao invés de um corvo, como o do poema, pode parecer estranha e até cômica, mas serve a um propósito. Mesmo que boa parte desta

\footnotetext{
${ }^{4} \mathrm{~A}$ ideia de que Edgar Allan Poe teria experienciado eventos semelhantes aos reproduzidos em sua obra está presente em outras obras contemporâneas, como no filme O Corvo (2012), de James McTeigue. Neste filme, tenta-se recriar o que poderia ter ocorrido a Edgar Allan Poe, interpretado por John Cusack, em seus últimos momentos de vida, que ainda são motivo de grande especulação. Para isto, vários elementos de seus contos são introduzidos no filme como tendo sido reais na vida de Poe. É preciso esclarecer, no entanto, que este "preenchimento das lacunas" da vida de Poe diz muito mais respeito à criatividade de autores contemporâneos que se apropriam de aspectos da vida e da obra de Poe do que a possíveis teorias que tentam explicar a obra de determinado artista com base em eventos de sua vida.
} 
série flerte com o sobrenatural, o grande objetivo é o de criar uma sensação de medo e de ameaça por meio de situações críveis dentro de uma lógica cotidiana. A presença de um corvo em uma rua movimentada de São Paulo até poderia ser bem recebida, posto que a ave carrega em si uma antiga simbologia de assombração, mas dificilmente atingiria seu propósito que é o de tentar criar um ambiente Gótico e perturbador a partir de uma realidade conhecida de muitos brasileiros. Como o corvo não é um pássaro existente nos ecossistemas da metrópole paulista, colocá-lo na série provocaria um efeito mais próximo do fantasioso ou, até mesmo, do surreal, o que não é seu objetivo. Logo, a escolha por um pombo, ave de grande abundância nos grandes centros urbanos brasileiros, mesmo parecendo estranha em um primeiro momento, permite ao público, já familiarizado com a obra de Poe, perceber a intertextualidade com um de seus mais famosos poemas sem causar nenhuma sensação de incoerência para o público que nunca teve contato com os textos de Poe, além de, também, representar certa ameaça, por ser uma ave transmissora de doenças em centros urbanos.

O uso do pombo para representar o corvo, ou mesmo da cidade de São Paulo como cenário para os contos de Poe, pode ser visto como outro fenômeno de hipertextualidade. Genette (1997) discorre sobre aproximação quando o processo de hipertextualidade apresenta um deslocamento, que pode ser cultural, geográfico e/ou temporal. A obra de Poe, representativa dos Estados Unidos do século 19, é transposta para outro contexto, onde há um forte deslocamento geográfico, temporal e cultural no maior centro urbano do Brasil no início do século 21. Assim, elementos como a presença de um pombo para substituir um corvo, uma oficina de carros para substituir um castelo medieval, ou mesmo mulheres solteiras e independentes vivendo sozinhas, tornam-se possíveis neste hipertexto em razão do deslocamento cultural realizado, elementos que dificilmente seriam possíveis na obra de Poe.

\section{Os EPISÓdIOS DE Contos do EdgaR}

Conforme mencionado anteriormente, o Gótico apresenta-se em diferentes momentos para expressar medos peculiares em diversos contextos culturais. Como o programa aqui analisado coloca-se no espaço urbano brasileiro contemporâneo, é importante discutir alguns desses possíveis medos que estão presentes neste contexto.

Para começar, é importante salientar a escolha por títulos de episódios que representam personagens femininas. Esta decisão pode ser vista como uma possível referência à citação de Poe, em seu ensaio A Filosofia da Composição, ao afirmar que "a morte de uma mulher bonita é, inquestionavelmente, o tema mais poético do mundo" (POE, 2008, p. 26). As mulheres presentes nesta série trazem características distintas daquelas do contexto cultural de Poe. As cinco protagonistas do programa são dotadas de algum tipo de independência, seja esta financeira, afetiva ou sexual, que dificilmente existiria no século 19. Enquanto no contexto 
cultural de Poe não teria espaço para mulheres empreendedoras ou envolvidas com política, Contos do Edgar mostra um contexto cultural em que mulheres já podem ter a independência financeira para serem empreendedoras e ter independência política para votar e assumir cargos políticos. Mesmo apresentando episódios com protagonistas feministas independentes, em um contexto social que lhes permite grande autonomia, esse mesmo contexto ainda aparece como um ambiente hostil a elas.

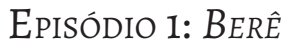

Inspirado no conto Berenice, o episódio de estreia da série traz a cantora Gabi Amarantos atuando como a protagonista que leva o nome do episódio. No conto sabemos que o casal de protagonistas são primos e que, embora tenham crescido juntos, são um tanto quanto diferentes:

Berenice e eu éramos primos e crescemos juntos nos salóes de meus antepassados. Todavia, crescemos de forma bastante diversa - eu, enterrado na melancolia de uma disposição enfermiça; ela, ágil, graciosa, transbordando de vitalidade (POE, 2018, p. 52).

No episódio mantém-se o grau de parentesco, sugerindo-se uma relação incestuosa que nunca chega a ser totalmente revelada, assim como também se mantém a diferença entre a melancolia do protagonista masculino - aqui chamado Cícero ao invés de Egeu - e a vitalidade da protagonista, que, no episódio, é uma cantora de bar. No início do episódio ela faz sucesso como cantora, com o nome artístico de "Berê Bitoca". Por ter dentes "feios", ela não se atreve a sorrir durante os shows, uma vez que esses mesmos dentes causam repulsa e vaias do público. Após uma cirurgia odontológica, então, ela passa a se apresentar com a expressão "O Sorriso de Berê"; a cirurgia fora paga pelo primo. Berê, porém, acaba sofrendo uma infecção bucal que a deixa com extrema dor, levando ao risco de amputação na região maxilar. O primo, que havia pago pela cirurgia, e que nutre sentimentos, no mínimo, questionáveis por Berê, alega que, por ter pago pelo procedimento, não permitiria que ela retirasse os dentes infeccionados, pois "os dentes são meus" - nas palavras de Cícero-, discurso comum a homens que enxergam o corpo de outras mulheres - sejam suas companheiras, filhas ou irmãs - como propriedade deles e não delas, sendo eles os que teriam o direito às decisões sobre o corpo delas. Além disso, a dona do bar e chefe de Berê também minimiza a dor que a cantora começa a sofrer no palco, forçando-a a se apresentar mesmo com dor excruciante, preocupada porque a "nova" e "sorridente" Berê houvera trazido um número considerável de clientes, aumentando a margem de lucro do estabelecimento.

De certa maneira, Berê é vítima da chamada "ditadura da beleza”, que a julga não por seu talento como cantora, mas por sua aparência, levando-a ao sofrimento físico. Além da 
cobrança do público para ficar "apresentável", há também uma cobrança das pessoas de seu ciclo mais próximo, como a chefe, que costumava se revelar como uma figura materna, e o próprio primo, que se mostrava como uma espécie de protetor. Considerando-se que há uma exigência no mundo ocidental para que o corpo feminino se adeque a padrões de belezas ditados por outras pessoas, mesmo quando há casos em que isto leva a distúrbios alimentares ou a procedimentos estéticos de risco, e sendo o Brasil um dos países com maior número de cirurgias plásticas no mundo, o episódio consegue, ao mesmo tempo que revisita a narrativa de Poe, trazer à tona uma discussão sobre os perigos que a mulher do século 21, especialmente a mulher brasileira, sofre.

\section{EPISÓDIO 2: PRISCILA}

Baseado no conto Metzengerstein, Priscila transpõe a narrativa com ambientação em castelos no interior da Hungria medieval para um bairro residencial e, aparentemente, pacato de São Paulo. O conto narra a história de duas famílias da nobreza que tinham conflitos por uma imprecisão quanto à divisão de suas terras, o que fazia com que cavalos - um de seus bens mais valiosos - acabassem sendo facilmente contestados por uma das famílias quando estes eram, na verdade, da outra.

Como é proposta da série retratar personagens que poderiam ser classificados dentro do que se costuma chamar, no Brasil, de "classe média baixa" - pessoas com uma certa independência financeira, que podem usar parte de sua renda para aquilo que se considera supérfluo, mas sem poder ir muito além disso financeiramente -, esse episódio traz duas famílias, cada uma dona de seu próprio negócio, mas que estão dentro desta "classe média baixa”. Em outras palavras, mesmo que eles sejam donos de seu próprio capital, são trabalhadores braçais que dependem do movimento diário de suas respectivas oficinas mecânicas. Ambas as famílias possuem oficina mecânica e, sendo vizinhos, acabam como concorrentes e, consequentemente, rivais. Os castelos húngaros são aqui trocados por oficinas modestas, e os cavalos são substituídos por motocicletas.

A protagonista do episódio, Priscila, torna-se vítima dessa rivalidade entre os homens das duas famílias, sendo a sua família representante de valores mais tradicionais e conservadores, enquanto a outra apresenta-se como transgressora desses mesmos valores. Mesmo que o episódio traga a questão das motocicletas, o que realmente se destaca é o fato da problemática social em relação à violência urbana gerada entre famílias vizinhas e que resulta na vitimização, principalmente, de mulheres, mesmo que estas não sejam as principais motivadoras destas disputas, mostrando, mais uma vez, como a violência de gênero é um problema da atualidade que a série soube retratar bem. Priscila é vítima do patriarcado, ora do pai, que tenta reprimila e decidir com quem ela deve ou não se relacionar, ora do seu companheiro, que, com seu comportamento inconsequente, acaba sendo responsável pelo desfecho sombrio. 


\section{EPISÓDIO 3: ÍRIS}

Dando continuidade à problemática dinâmica social entre vizinhos, o episódio Íris aprofunda esse conflito em um ambiente ainda mais claustrofóbico e restritivo. Se em Priscila a convivência entre vizinhos que moravam numa mesma rua, mas em quadras diferentes, tendo uma rua pública para separá-los, já era conflituosa, as personagens de Íris vivem em um prédio de apartamentos onde os limites entre espaço público e privado são muito mais nebulosos, aumentando a tensão entre personagens.

Baseado no conto O Coração Denunciador, o episódio Íris também traz uma relação entre assassino e vítima - uma pessoa idosa e uma pessoa jovem. Diferentemente do conto, porém, a classificação entre algoz e vítima não é meramente invertida, mas subvertida. Há uma inversão primeira, pois a personagem jovem - que no conto é um narrador anônimo e masculino e na série é uma jovem chamada Íris -é quem sofre o assassinato, enquanto o velho é quem comete o crime. Na medida em que no conto o próprio narrador menciona que o velho nunca lhe fizera nenhum mal que justificasse uma agressão ou o consequente assassinato, no episódio da série a relação entre o velho e Íris se torna cada vez mais insustentável, pois, desde sempre, um parece estar disposto a irritar o outro. Tal relação poderia ser vista como uma possível subversão entre hipotexto e hipertexto, uma vez que o episódio da série permite enxergar ambos os protagonistas tanto como vítimas quanto algozes.

Ainda que somente um deles cometa o assassinato e apenas um seja uma vítima fatal, a relação entre eles é complexa. Em determinado momento do episódio, por exemplo, há uma festa no apartamento de Íris com diversos jovens e uso de drogas ilícitas. O protagonista idoso faz uma denúncia anônima para a polícia e a festa é encerrada por esta. Nessa situação, Íris ocupa o papel de algoz, ainda mais se pensarmos que o velho, que vive apenas com a esposa, também idosa, está em estado de vulnerabilidade diante da possível violência decorrente do tráfico de drogas, algo potencializado por aqueles que foram convidados por Íris para uma festa em sua casa. Vivendo em um prédio com apartamentos "colados" uns aos outros, dezenas de jovens fazendo uso de narcóticos representam um perigo real para o casal idoso, que dificilmente teria como se defender ou escapar na ocasião de um possível assalto ou agressão decorrente do uso de drogas que ocorria na porta ao lado.

Esse episódio dialoga com o anterior (Priscila) ao também abordar a questão da violência urbana brasileira que surge entre vizinhos e que termina, muitas vezes, em morte. Se em Priscila pelo menos há um espaço aberto para separar as residências, em Íris é como se os rivais vivessem "sob o mesmo teto", tornando o convívio ainda mais conflitante. Independente do arranjo de vizinhança existente em cada episódio, porém, em ambos é a personagem feminina que se torna a vítima fatal do conflito. 


\section{Episódio 4: CeCÍlia}

Inspirado no conto A Máscara da Morte Rubra, o episódio Cecília traz a protagonista como dona de uma loja de fantasias e adereços e, assim como no conto, preparando-se para as festividades do carnaval, desta vez o brasileiro.

Dentre os episódios, o que talvez melhor bem apresente a questão da violência contra a mulher na atualidade seja esse. A personagem-título do episódio é a única de toda a série que não está romanticamente envolvida com nenhum homem ${ }^{5}$, sendo apresentada como uma mulher de negócios independente, que vive sozinha. Mesmo, porém, sendo uma mulher independente, talvez por viver num país onde a cultura patriarcal ainda é forte, ela não consegue se proteger da iminente violência urbana e sexual'

No conto, o protagonista, o Príncipe Próspero, ao saber da existência de uma ameaça externa - uma epidemia fatal -, tranca-se e protege seu castelo das formas mais sofisticadas para sua época, proibindo expressamente a saída ou entrada de qualquer pessoa ali. Próspero manda fechar pontes, portões ou quaisquer outros meios de acesso ao castelo, enquanto realiza um grande baile de máscaras, acreditando estar a salvo da contaminação externa.

Da mesma maneira, Cecília também se protege com grades, câmeras e alarmes, desta vez contra o que poderíamos chamar de uma "epidemia social", que é a violência contra mulheres. Além da ameaça física, há uma permanente ameaça psicológica, pois Cecília tem pesadelos e vê constantes notícias de casos como o seu, sem nunca conseguir discernir fatos de possíveis alucinações e sem ter êxito em reconhecer se seu agressor fora o mesmo preso pela polícia com igual acusação. Assim como ocorre com Próspero no conto, a violência e a morte mostram-se iminentes e mais poderosas do que qualquer artefato ou tecnologia de proteção empregado, seja no castelo medieval de Próspero seja na residência urbana contemporânea de Cecília.

\section{EPISÓDIO FINAL: LENORA}

Inspirado nos contos O Gato Preto e O Barril de Amontillado, o episódio que encerra a série se intitula Lenora, a esposa de Edgar, protagonista da série, em uma clara referência à mulher mencionada no poema $O$ Corvo. A menção à Lenora surge já no primeiro episódio da série, em um diálogo entre Edgar e Fortunato, mas sem que se saiba muito sobre ela. Aparentemente,

\footnotetext{
${ }^{5}$ A única relação afetiva sobre a qual sabemos é uma amiga e confidente de Cecília. Há uma cena, durante uma festa de Carnaval, em que as duas se beijam, mas o contexto sugere muito mais se tratar de um beijo "por diversão" do que um envolvimento romântico.

${ }^{6} E$ É interessante que, no ano em que a série foi exibida, observou-se que casos de violência sexual tiveram um aumento significativo no Brasil: de acordo com o Anuário Brasileiro de Segurança Pública, de 2013, casos de estupro aumentaram mais de $18 \%$ de 2011 para 2012. Tal crescimento aponta para o que foi dito anteriormente sobre a relação entre gótica e sociedade, de que o Gótico é uma forma artística de se expressar e mensurar os medos que assombram diferentes contextos culturais, evidenciando que, apesar de todas as conquistas que a mulher obteve ao longo das últimas décadas, isso não impediu o crescimento de violência, estupro e feminicídio.
} 
ela desapareceu sem deixar vestígios, com a suposição, por parte de Edgar e de Fortunato, de que ela teria simplesmente abandonado o relacionamento com o marido e, ao invés de confrontá-lo para oficializar o término, teria decidido fugir para evitar o incômodo da separação.

Esse episódio, de um ponto de vista da adaptação, talvez seja o mais rico e complexo de todos os da série, pois 1) é o único que busca adaptar mais de um conto, além da referência a O Corvo; e 2) é o que busca fechar todo o arco narrativo maior da série, diferente dos arcos narrativos individuais de cada episódio.

A relação entre Edgar e Lenora e a animosidade entre Lenora e Fortunato são explicitadas por meio da adaptação narrativa de O Gato Preto. Fortunato, dono de um bar, entra em conflito com Lenora, pois ela é dona de um gato. Sendo o bar alvo de inspeções da vigilância sanitária, ele teme que a presença do gato no bar seja motivo para que a licença de funcionamento seja cassada. Lenora, por outro lado, afeita ao mascote, acredita que Fortunato seja demasiado cruel com o animal. Um simples desentendimento entre os dois acaba tornando-se um peso desproporcional para Edgar, que se vê dividido entre o melhor amigo e a esposa, vendo-se obrigado a tomar partido para resolver o conflito, mas sem a coragem para tal.

Já a relação entre Edgar e Fortunato é melhor desenvolvida mediante a adaptação do conto O Barril de Amontillado. Como Fortunato - do episódio - possui o mesmo nome da personagem do conto que sucede como vítima fatal do protagonista, a replicação do nome não é casual, posto que o desejo de vingança resulta na vítima sendo emparedada viva. No conto, a motivação vingativa de Monstresor - protagonista do conto - não fica clara, o que aumenta a sensação de estarmos diante de um narrador pouco confiável. No episódio, sugere-se fortemente que Fortunato é inocente e que a culpa que o protagonista atribui ao amigo é, na verdade, totalmente sua. Por estarmos tratando de uma obra audiovisual que, como já foi apontado, trata da problemática da violência contra mulheres na contemporaneidade urbana brasileira, é importante lembrar que em grande parte dos casos de violência há um discurso muito presente na sociedade que tenta, nesse tipo de crime, culpar a vítima pela atitude do agressor ${ }^{7}$. Edgar, que se apresenta como uma pessoa misteriosa e não muito equilibrada mentalmente, é o único culpado pela morte da própria esposa, como descobrimos nos flashbacks desse episódio. Não tendo a capacidade psicológica para lidar com o conflito entre esposa e melhor amigo, Edgar opta, primeiramente, pelo assassinato da esposa. Sem conseguir verbalizar o ocorrido, e para se livrar da punição, ele cria para si - e para os outros - uma narrativa sociopata de que fora Fortunato o responsável pelo desaparecimento de Lenora. Como em um crime passional, quando, em nome da "legítima defesa da honra", um homem se vê no direito

\footnotetext{
${ }^{7}$ Além do lento processo histórico que só reconheceu homens e mulheres em pé de igualdade recentemente, e da Lei do Feminicídio de 2015, esse tipo de discurso de culpar a vítima ainda se faz presente em diferentes instâncias da sociedade. Um caso recente que merece destaque é o de Mari Ferrer, vítima de estupro, cuja situação chama atenção pela culpabilização da vítima, desde os próprios juízes do caso que julgaram o caso como "estupro culposo", como se não houvesse "intenção" por parte dos agressores, e de comunicadores, como Rodrigo Contantino, que, ao comentar o caso, disse que, se fosse sua filha a vítima, antes de levar o caso à polícia ele iria perguntar se ela havia "bebido demais", para, então, decidir se a filha "merecia ser castigada" (FUZEIRA, 2020).
} 
de tirar a vida da esposa e de um suposto amante, Edgar verbaliza para si mesmo que a culpa de tudo era unicamente responsabilidade de Fortunato, como uma espécie de justificativa de sua sociopatia para se sentir no direito de ter cometido esses crimes, assim como Monstresor que, sem conseguir explicar o que Fortunato fizera de tão horrível, se acha no direito de matar o amigo de maneira extremamente cruel.

\section{Considerações Finais}

Este trabalho buscou analisar os processos de transposição que a série televisiva Contos do Edgar fez em relação aos contos de Edgar Allan Poe, pensando a questão de transpor a mídia e a diegese dos contos para outro contexto cultural e temporal. Além disso, por se tratar de um escritor referência para a literatura gótica, este estudo também buscou entender o que tornaria essa releitura gótica, uma vez que a ambientação e a narrativa são transformadas a ponto de substituírem elementos temáticos. Ao se pensar que a série intitula seus episódios com nomes de mulheres, todas vítimas fatais de algum tipo de violência - e uma violência que surge de pessoas próximas a elas -, entende-se melhor que o Gótico da série, ou seja, o tipo de medo e ansiedade social que ela busca retratar, é justamente a problemática da violência contra a mulher, algo presente e crescente no Brasil do século 21.

De forma geral, percebe-se que a obra de Edgar Allan Poe permanece atual em diferentes contextos. O fato de diversas obras de Poe terem sido adaptadas para outras linguagens é evidência de que sua obra permanece viva, mesmo um século e meio após sua morte. Da mesma maneira, o programa Contos do Edgar consegue recriar, em um Brasil contemporâneo, alguns anseios experimentados pelas personagens de Poe. Ao trazer elementos da obra de Poe para a sociedade contemporânea brasileira, portanto, Fernando Meirelles mostra que a humanidade, independentemente de sua época, situação e lugar, enfrenta semelhantes medos, busca semelhantes objetivos, procura semelhantes realizações em suas vidas e precisa vencer semelhantes obstáculos.

Assim, pode-se afirmar que Contos do Edgar é uma obra que possui grande força gótica por expressar um dos grandes medos de seu contexto de produção: a violência, de diversas formas e origens, contra mulheres, em uma sociedade que, em tese, já superou as diferenças legais entre homens e mulheres. 


\section{REFERÊNCIAS}

ANUÁRIO BRASILEIRO DE SEGURANÇA PÚBLICA. Editado pelo Fórum Brasileiro de Segurança Pública, ano 7, 2013.

BRUHM, Steven. The contemporary Gothic: why we need it. In: HOGLE, Jerrold E. (ed.). The Cambridge Companion to Gothic Literature. New York: Cambridge University Press, 2002.

CONTOS DO EDGAR. Produção Fernando Meirelles. Fox International, 2013.

FUZEIRA, Victor. Caso Mari Ferrer: colunista diz que não denunciaria estupradores da filha. Metrópoles, Brasília, 4 nov. 2020. Disponível em: https://www.metropoles.com/brasil/casomari-ferrer-colunista-diz-que-nao-denunciaria-estupradores-da-filha. Acesso em: 29 jun. 2021.

GENETTE, Geràrd. Palimpsests: Literature in second degree. Translated by Channa Newman and Claude Doubinsky. Lincoln: University of Nebraska Press, 1997.

HOGLE, Jerrold B. The Gothic in Western Culture. In: HOGLE, Jerrold E. (ed.). The Cambridge Companion to Gothic Literature. New York: Cambridge University Press, 2002.

HUTCHEON, Linda. Uma teoria da adaptação. Trad. André Cechinel. 2. ed. Florianópolis: Editora da UFSC, 2013.

LONGUEIL, Alfred E. The Word "Gothic" in Eighteenth Century Criticism. In: Modern Language Notes, London: The Johns Hopkins University Press, v. 38, n. 8, 1923.

POE, Edgar Allan. A carta roubada e outras histórias de terror e mistério. Trad. William Lagos. Porto Alegre: L\&PM, 2018.

POE, Edgar Allan. Filosofia da composição. Trad. Léa Viveiros de Castro. Rio de Janeiro: Editora 7 Letras, 2008.

VALAREZO, Max. Terror cósmico: por que é tão difícil de filmar? Canal Entre Planos, 2020 (15m14s). Disponível em: https://www.youtube.com/watch?v=dikqFaJQ1zE. Acesso em: 19 fev. 2021.

Recebido para publicação em: 6 jul. 2021. Aceito para publicação em: 4 out. 2021. 